This document is confidential and is proprietary to the American Chemical Society and its authors. Do not copy or disclose without written permission. If you have received this item in error, notify the sender and delete all copies.

\title{
Enriching the Reticular Chemistry Repertoire with Minimal Edge-Transitive related Nets: Access to Highly-coordinated MOFs based on Double Six-membered Rings as net-coded Building Units.
}

\begin{tabular}{|c|c|}
\hline Journal: & Journal of the American Chemical Society \\
\hline Manuscript ID & ja-2019-11260c.R1 \\
\hline Manuscript Type: & Article \\
\hline $\begin{array}{r}\text { Date Submitted by the } \\
\text { Author: }\end{array}$ & 01-Dec-2019 \\
\hline Complete List of Authors: & $\begin{array}{l}\text { Chen, Zhijie; King Abdullah University of Science and Technology, } \\
\text { Chemical and Life Sciences and Engineering Division; Northwestern } \\
\text { University, Chemistry } \\
\text { Thiam, Zeynabou; King Abdullah University of Science and Technology, } \\
\text { Shkurenko, Aleksander; King Abdullah University of Science and } \\
\text { Technology, Advanced Membranes \& Porous Materials Center (AMPM) } \\
\text { Weselinski, Lukasz; King Abdullah University of Science and Technology, } \\
\text { Chemical and Life Sciences and Engineering Division; Michigan } \\
\text { Technological University, Department of Chemistry } \\
\text { Adil, Karim; King Abdullah University of Science and Technology, } \\
\text { Chemical Science } \\
\text { Jiang, Hao; King Abdullah University of Science and Technology, } \\
\text { Chemical and Life Sciences and Engineering Division } \\
\text { Alezi, Dalal; King Abdullah University of Science and Technology, } \\
\text { Chemical and Life Sciences and Engineering Division } \\
\text { Assen, Ayalew; King Abdullah University of Science and Technology, } \\
\text { Chemical Science } \\
\text { O'Keeffe, Michael; Arizona State University, Chemistry Department } \\
\text { Eddaoudi, Mohamed; King Abdullah University of Science and } \\
\text { Technology, Chemical and Life Sciences and Engineering Division }\end{array}$ \\
\hline
\end{tabular}

\section{SCHOLARONE Manuscripts}




\section{INTRODUCTION}

Metal-organic frameworks $(\mathrm{MOFs})^{1-2}$ represent a distinct class of porous materials with prospect applications pertaining to catalysis ${ }^{3-4}$, selective sensing ${ }^{5-6}$, gas storage ${ }^{7-9}$ and separation $^{10-12}$. Advances in MOF chemistry afforded the successful practice of reticular chemistry using pre-selected metalcontaining molecular building blocks (MBBs), that is, welldefined molecular clusters rather than from single atoms. ${ }^{13-15}$ The MBB approach permitted access to MOFs with simple topologies, such as minimal edge-transitive nets (especially those with only one or two kinds of edges) ${ }^{16-23}$ Isolation of the reaction conditions that consistently allow the in situ formation of the desired inorganic MBB (especially highlyconnected MBB with connectivity higher than eight), matching the augmented basic building units (vertex figures) of the targeted net, is the key prerequisite for the successful implementation of the MBB approach for the rational design and construction of MOFs. ${ }^{17,20}$

Minimal edge-transitive 3-periodic nets, enclosing edgetransitive hierarchical building units that are distinctively coding for the associated net, are of special interest in crystal chemistry. ${ }^{16,}{ }^{24}$ Practically, highly-coordinated minimal edgetransitive nets with at least one node having a connectivity $\mathrm{n} \geq 12$ are appropriate targets in crystal chemistry, as they not only limit the number of outcome nets for the assembly of their associated highly-connected building blocks but also are the most amenable nets to be realized in synthesis. We defined those highly-coordinated building units as net-coded building units (net-cBUs) because they embed unique geometrical information coding precisely for a targeted net. One distinctive way to yield highly-coordinated minimal edge-transitive nets is to generate related nets from the edge-transitive net by replacing one of the nodes with an edge-transitive binodal group (Figure 1). ${ }^{24}$ For instance, nets with transitivity [32] (i.e. three types of nodes and two types of edges) are generated from nets with transitivity [21] with vertices type A and type B, where vertex $\mathrm{A}$ is replaced by a group of linked vertices. If the coordination number of B is increased the new net is a related net.

The newly generated minimal edge-transitive related nets based on the double six-membered ring (d6R or hexagonal prism), offer great potential as blueprint nets for the rational design and deliberate assembly of highly-connected crystalline materials from their net-cBUs, thanks to the generally high coordination number for one of the nodes. All of those novel highly-coordinated related nets with transitivity [32] have been included in the Reticular Chemistry Structural Resource 
(RCSR) database, and will offer a new and unique toolbox for the design of periodic solids such as MOFs. ${ }^{25}$

Several key prerequisites have to be delineated in order to tackle the prospective design and rational construction of the highly-connected MOF platform using the minimal edgetransitive nets based on $\mathrm{d} 6 \mathrm{R}$ as a net-cBU. These include, most notably readily access to i) 12-connected (12-c) hexagonal prismatic (d6R) inorganic polynuclear clusters, matching the vertex figure of the $d 6 \mathrm{R}$ building unit; ii) the appropriate highly-connected polycarboxylate ligands or cluster-based branched building units, which can be viewed as tertiary building units (i.e. the combination of triangles and square or hexagon); iii) the suitable solvothermal reaction conditions that permit the assembly of single crystals for the conclusive structural determination, from the combination of the aforementioned inorganic and organic MBBs.

In this contribution, we systematically generated minimal edge-transitive related nets with transitivity [32] from parent edge-transitive nets (transitivity [21] or [11]), with a specific focus on the highly-coordinated related net based on the d6R (i.e. kce, epw, urp, urx, kex net). In this work, three of these minimal edge-transitive related nets have been used as a blueprint net guiding the rational design and assembly of highlyconnected MOFs based on 12-c hexagonal prismatic (d6R) building units. The pre-programmed 8-c organic ligand, containing the intricate triangular and square building units, combined with the previously reported 12-c hexagonal prismatic rare-earth (RE) nonanuclear $\left[\mathrm{RE}_{9}\left(\mu_{3}-\mathrm{O}\right)_{2}\left(\mu_{3}-\mathrm{OH}\right)_{12}\left(\mathrm{O}_{2} \mathrm{C}-\right)_{12}\right]$ carboxylate-based cluster, led to the formation of the first kceMOF based on the $(3,4,12)$-c soc-related kce net.

The (3,6,12)-c kex (triangle, hexagon, and d6R) and urx (triangle, octahedron trigonal anti prism), and d6R) nets are the $(6,6)-c$ nia-related nets (octahedron and trigonal prism). Markedly, we successfully constructed the first RE-kex-MOF, RE-kex-MOF-1, by employing the aforementioned nonanuclear carboxylate-based cluster as the requisite $12-\mathrm{c} d 6 \mathrm{R}$ building unit and the recently reported dodecacarboxylate ligand, 1,2,3,4,5,6-hexakis[3,5-bis(4carboxyphenyl)phenoxymethyl]benzene ( $\left.\mathrm{H}_{12} \mathrm{HBCPB}\right)$, embedding elaborate triangular arms and hexagonal core. ${ }^{20}$ Alternatively, this 12 -c organic MBB can act as a 12-c MBB, conceivably affording the positioning of the carbon centers of the twelve carboxylate groups on the vertices of the hexagonal prism. Thus, the RE-kex-MOF-1 can also be regarded as a zeolite-like MOF (ZMOF) $)^{26-27}$ based on $(4,4)$-c afx net with pure d6Rs as composite building units. It is worth to mention that this is the first ZMOF based on the pure organic d6R, presenting a new approach for the rational construction of ZMOFs through the composite building unit approach.

Moreover, the careful combination of heterobifunctional triangular tetrazole-based ligand, 5'-(1H-tetrazol-5-yl)- 1, $1^{\prime}: 3^{\prime}, 1^{\prime \prime}$ terphenyl-4,4"-dicarboxylic acid ( H $_{3}$ TTDA $)^{28}$, and the polynuclear RE clusters, led to the construction of the highlyconnected MOF based on the $(3,6,12)$-c urx net, namely REurx-MOF-1. The benzene-1,3-dibenzoate part coordinated to the nonanuclear carboxylate-based clusters (d6Rs) and the tetrazolate moiety directed the formation of tetrazolate-based hexanuclear RE cluster. Remarkably, this tetrazolate-based hexanuclear cluster is 6-connected instead of 12-connected, as previously reported hexanuclear cluster $\left[\mathrm{RE}_{6}\left(\mu_{3}-\right.\right.$ $\left.\mathrm{OH})_{8}\left(\mathrm{O}_{2} \mathrm{C}-\right)_{6}\left(\mathrm{~N}_{4} \mathrm{C}-\right)_{6}\right]$ in RE-fcu-MOF-1 with heterofunctional ditopic linkers. ${ }^{17}$ Additionally, this 6-connected hexanuclear cluster can be viewed as trigonal antiprismatic building units.
It is to be noted that it represents the first example of urxMOF with triangle, trigonal anti prism, and $\mathrm{d} 6 \mathrm{R}$ as building units.

Therefore in this study the deliberate construction of highlyconnected MOFs based on highly-coordinated and minimal edge-transitive related nets from their related net-cBUs illustrates: i) the importance of highly-connected minimal edgetransitive nets as appropriate blueprints for the design and assembly of MOFs; ii) the benefits of related nets as a credible pathway for the design and construction of 3-periodic crystalline extended frameworks; iii) polynuclear inorganic clusters with connectivity of 12 or greater as a reliable route to readily access the requisite net-cBUs with the looked-for directional and structural information; iv) the prominence of polytopic branched ligands as net-cBUs with precise embedded geometrical information to code matchlessly and distinctively a selected net. 


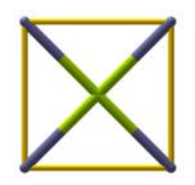

III

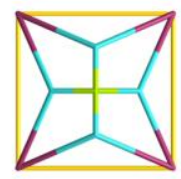

soc net

$(4,6)-c$ net, transitivity [ $\left[\begin{array}{lll}2 & 1 & 2\end{array}\right]$

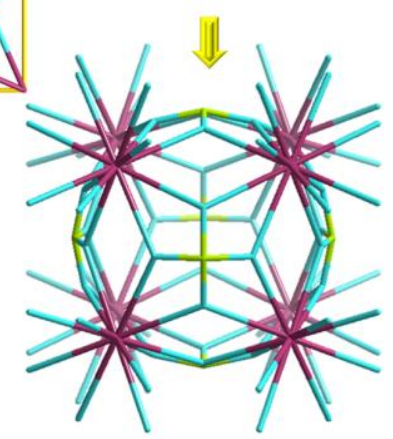

soc-related kce net

$(3,4,12)$-c net, transitivity [ [ $\left.\begin{array}{llll}3 & 2 & 3 & 2\end{array}\right]$

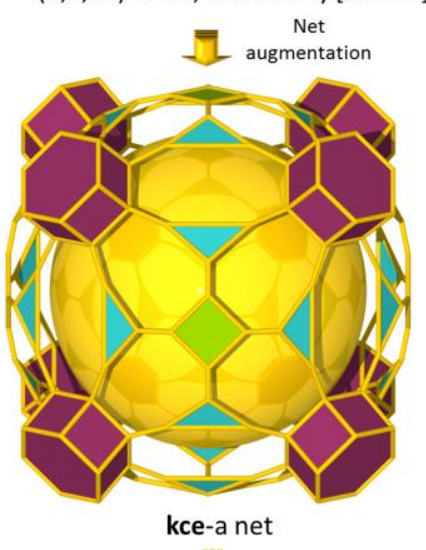

IIII

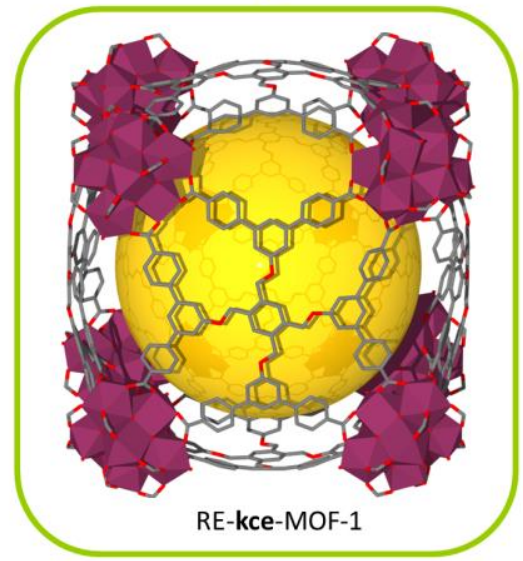

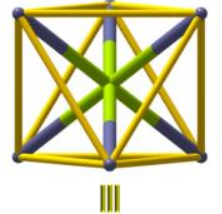
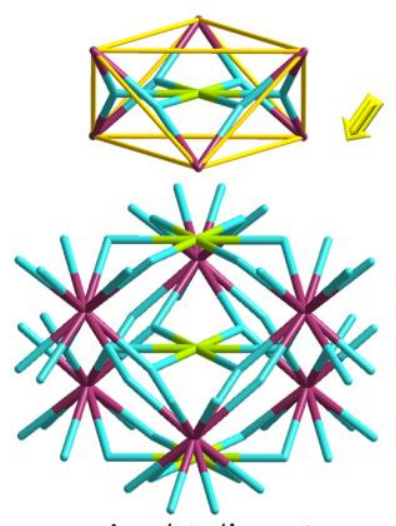

nia-related kex net

$(3,6,12)$-c net, transitivity [3 244 3]

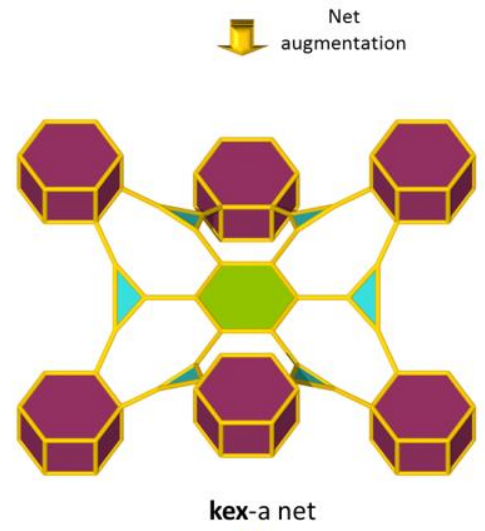

||II

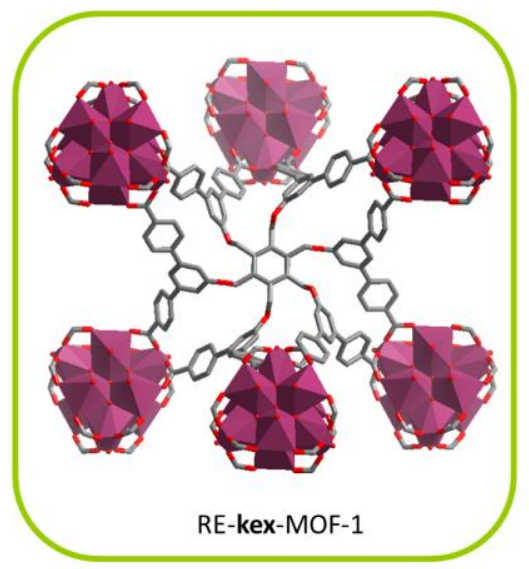

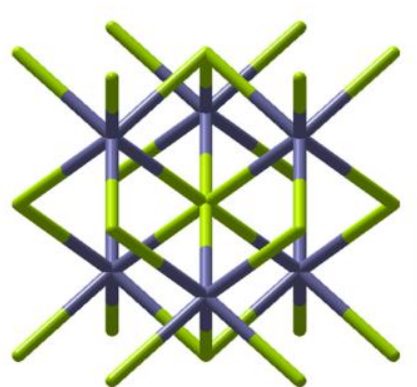

nia net

$(6,6)-c$ net, transitivity [ $\left[\begin{array}{lll}2 & 1 & 2\end{array}\right]$

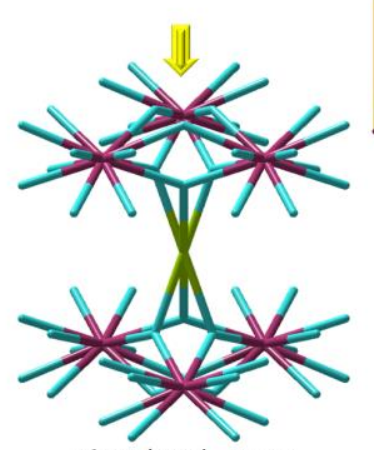

nia-related urx net

(3,6,12)-c net, transitivity [3 244 3]

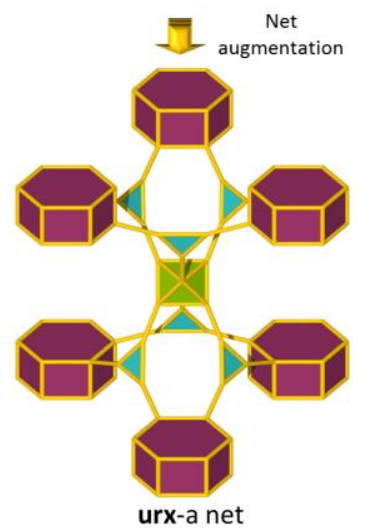

||I

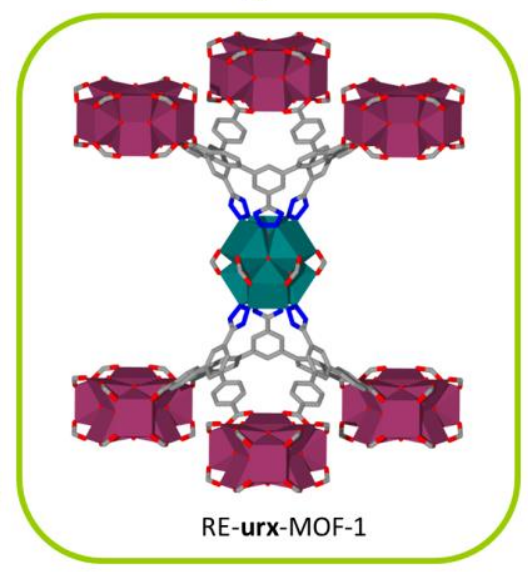

Figure 1. Generation of minimal edge-transitive net (transitivity [32]) from edge-transitive net (transitivity [21]) by replacing one of the nodes with an edge-transitive binodal group. RE, C, O, and $\mathrm{N}$ are represented by purple/sea green, gray, red and blue, respectively, and $\mathrm{H}$ atoms and solvent molecules are omitted for clarity. RE atoms are represented as polyhedra. 


\section{RESULTS AND DISCUSSION}

Generation of minimal edge-transitive related net.

At the outset of this study, the parent edge-transitive net ${ }^{29}$ was employed by replacing one of the nodes with an edge-transitive binodal group to generate the minimal edge-transitive related net. A newly generated net is defined as a related net when the coordination number of $\mathrm{B}$ is increased for a parent net with vertices type $\mathrm{A}$ and $\mathrm{B}$, where vertex $\mathrm{A}$ is replaced by a group of linked vertices. If the coordination number of $B$ remains the same the new net is a derived net, and this kind of net has been discussed and reviewed previously. ${ }^{16,24}$ For instance, as illustrated in Figure 1, the $(3,4,12)$-c kce net is generated from the $(4,6)$-c soc net by replacing 4-c square into a group of nodes (i.e. one kind of triangles and one square), and the coordination number of the other node is increased from 6 for octahedron in the soc net to 12 for hexagonal prism (d6R) in the kce net. Thus, kce net is a socrelated net.

Table. 1 Edge-transitive binodal parent nets and their minimal edge-transitive related nets.

\begin{tabular}{|c|c|c|c|c|c|c|}
\hline $\mathrm{VF}^{\mathrm{a}}$ & Parent net $\left(\mathrm{SPGR}^{\mathrm{b}}\right)$ & $\mathrm{CF}^{\mathrm{c}}$ & Operation $^{\mathrm{d}}$ & Related $^{\mathrm{e}}$ & $\mathrm{CF}^{\mathrm{c}}$ & SPGR $^{b}$ \\
\hline \multirow[t]{5}{*}{$\mathrm{O}$} & pcu-b $(F m \overline{3 m})$ & $\mathrm{O}, \mathrm{O}$ & $O-1-6 a^{\mathrm{f}}$ & epu & {$[\mathrm{H} 3] \mathrm{X}_{2}$} & $R \overline{3 m}$ \\
\hline & & & $O-1-6 b^{f}$ & epv & {$[\mathrm{O} 3] \mathrm{X}_{2}$} & $R \overline{3 m}$ \\
\hline & nia $\left(P 6_{3} / m m c\right)$ & $\mathrm{O}, \mathrm{P}$ & $0-1-6 a^{f}$ & kex & {$[\mathrm{H} 3] \mathrm{X}_{2}$} & $\mathrm{~Pb}_{3} / \mathrm{mmc}$ \\
\hline & & & $0-1-6 b^{f}$ & urx & {$[\mathrm{O} 3] \mathrm{X}_{2}$} & $\mathrm{~Pb}_{3} / \mathrm{mmc}$ \\
\hline & $\operatorname{soc}(\operatorname{Im} \overline{3 m})$ & $\mathrm{S}, \mathrm{O}$ & $S-1-4$ & kce & {$[\mathrm{S} 3] \mathrm{X}_{2}$} & $\operatorname{Im} \overline{3 m}$ \\
\hline \multirow[t]{2}{*}{$\mathrm{P}$} & acs-b $(P \overline{6 m} 2)$ & $\mathrm{P}, \mathrm{P}$ & P-1-6 & dnm & {$[\mathrm{P} 3] \mathrm{X}_{2}$} & $P \overline{6 m} 2$ \\
\hline & nia $\left(P 6_{3} / m m c\right)$ & $\mathrm{P}, \mathrm{O}$ & P-1-6 & dnn & {$[\mathrm{P} 3] \mathrm{X}_{2}$} & $P 6_{3} / \mathrm{mmc}$ \\
\hline $\mathrm{H}$ & hxg-b $(F d \overline{3 m})$ & $\mathrm{H}, \mathrm{H}$ & H-1-6 & epw & {$[\mathrm{H} 3] \mathrm{X}_{2}$} & $F d \overline{3 m}$ \\
\hline $\mathrm{C}$ & ocu $(\operatorname{Im} \overline{3 m})$ & $\mathrm{O}, \mathrm{C}$ & C-1-8 & urp & {$[\mathrm{C} 3] \mathrm{X}_{2}$} & $\operatorname{Im} \overline{3 m}$ \\
\hline $\mathrm{U}$ & $\operatorname{mgc}(F d \overline{3 m})$ & $\mathrm{H}, \mathrm{U}$ & $\mathrm{U}-1-12$ & dny & {$[\mathrm{B} 3] \mathrm{X}_{2}$} & $F d \overline{3 m}$ \\
\hline \multirow[t]{3}{*}{$\mathrm{X}$} & $\operatorname{shp}(P 6 / \mathrm{mmm})$ & $\mathrm{S}, \mathrm{X}$ & $\mathrm{X}-1-12$ & pek & $\mathrm{C}_{2}[3 \mathrm{X}]$ & $P 6 / \mathrm{mmm}$ \\
\hline & alb $(P 6 / \mathrm{mmm})$ & $\mathrm{P}, \mathrm{X}$ & $X-1-6 e$ & alc & {$[\mathrm{HQ}] \mathrm{X}_{4}$} & $P 6 / \mathrm{mmm}$ \\
\hline & & & $\mathrm{X}-1-12$ & aea & {$[\mathrm{X} 3] \mathrm{X}_{2}$} & $P 6 / \mathrm{mmm}$ \\
\hline
\end{tabular}

${ }^{\mathrm{a}} \mathrm{VF}=$ vertex figures, indicating the vertex figures of the parent edge-transitive nets.

${ }^{\mathrm{b}} \mathrm{SPGR}=$ space group, indicating the space group of parent nets and their generated related nets.

${ }^{\mathrm{c}} \mathrm{CF}=$ coordination figure (shape of coordination). For binodal parent nets, $\mathrm{CF}$ referred to W,W. For example, $\mathrm{S}, \mathrm{O}$ is the $\mathrm{CF}$ for soc net. For trinodal related nets, the $\mathrm{CF}$ is specified as the form $\left[\mathrm{X}_{m} \mathrm{Y}_{\mathrm{Z}}\right.$, indicating $\mathrm{Y}$ is linked to $m \mathrm{X}$ and $n \mathrm{Z}$ and $\left[\mathrm{X}_{m} \mathrm{Y}\right]$ is derived from the parent net. For the $\mathrm{CF}: 3=$ triangle, $\mathrm{S}=$ square, $\mathrm{Q}=$ square pyramid, $\mathrm{O}=$ octahedron, $\mathrm{P}=$ trigonal prism, $\mathrm{H}=$ hexagon, $\mathrm{C}=$ cube, $\mathrm{X}=$ hexagonal prism, $\mathrm{U}=$ truncated tetrahedron, $\mathrm{B}=$ cuboctahedron.

${ }^{\mathrm{d}} \mathrm{W}-n_{1}-n_{2}, \mathrm{~W}$ represent overall shape of the building block (e.g. $\mathrm{P}=$ trigonal prism); $n_{1}$ denotes the number of one node or several nodes in the center of this building block; $n_{2}$ represents the number of derived nodes between the central nodes and vertices.

${ }^{\mathrm{e}}$ Related nets based on the double six-membered ring (d6R or hexagonal prism).

${ }^{\mathrm{f}}$ The replacement of the 6-c octahedral node $(\mathrm{O})$ with a group of two kinds of nodes. O-1-6a denotes the central node is connected to six planar nodes, and the generated net contains hexagonal nodes. O-1-6b denotes the central node is connected to six nodes sitting in octahedral geometry, and the generated net contains 6-c octahedral nodes. 
RE-kce-MOF-1 Platform.

The d6R multinuclear clusters have been explored to construct highly-connected and stable MOFs with versatile properties. ${ }^{19-}$ 20, 30-32 Introduction of the dendritic organic linker dramatically limited the possible outputs of the MOF products; however, it remains challenging to synthesize highly-connected MOFs with dendritic organic ligands having more than six carboxylates due to the difficulty and complexity of synthesis techniques. Specially, to the best of our knowledge, there is no example of RE-MOFs based on the highly-connected nets with at least one node $\geq 12$ constructed from dendric organic ligand with more than eight carboxylates.

The $(3,4,12)$-c kce net with transitivity [3232], containing one type of triangles, one square, and d6R building unit, was employed as a suitable blueprint for the rational construction of MOFs. To target the aforementioned highly-coordinated kceMOFs, a noticeable strategy was to design a novel polytopic branched ligand with pre-coded geometrical information uniquely matching the selected net, i.e. square and triangular arms. This branched linker can furthermore guide the formation of previous reported d6R-shaped polynuclear clusters in proper reaction conditions, eventually resulting in the targeted kce-MOF.

Indeed, reactions between $\mathrm{Y}\left(\mathrm{NO}_{3}\right)_{3} \cdot 6 \mathrm{H}_{2} \mathrm{O}$ and 1,2,4,5tetrakis[3,5-bis(4-carboxyphenyl)phenoxymethyl]benzene

$\left(\mathrm{H}_{8} \mathrm{TBCPB}\right)$ (Figure S1a-d), in the presence of 2fluorobenzoic acid (2-FBA) in an $\mathrm{N}, \mathrm{N}$-dimethylformamide (DMF)/chlorobenzene/water solution yielded colorless polyhedral crystals, formulated by single crystal X-ray diffraction study $\quad(\mathrm{SCXRD}) \quad$ as $\quad\left|(\mathrm{DMA})_{3}\right|\left[\mathrm{Y}_{9}\left(\mu_{3}-\mathrm{O}\right)_{2}\left(\mu_{3^{-}}\right.\right.$ $\left.\mathrm{OH})_{12}(\mathrm{OH})_{2}\left(\mathrm{H}_{2} \mathrm{O}\right)_{7}(\mathrm{TBCPB})_{1.5}\right] \cdot(\text { solv })_{x} \quad$ (kce-MOF-1) (1) (DMA = dimethylammonium cation and solv = solvent $)$ ( Table S1; Figures 2 and S2). The SCXRD study discloses that compound 1 crystallizes in the cubic space group $I m-3 m$ with $a=43.475(2) \AA$ and $V=82170(10) \AA^{3}$. Analysis of the resultant crystal structure of 1 revealed the in situ formation of highly-connected yttrium (Y) polynuclear carboxylate-based clusters, namely a 12-c nonanuclear clusters, $\left[\mathrm{RE}_{9}\left(\mu_{3}-\mathrm{O}\right)_{2}\left(\mu_{3^{-}}\right.\right.$ $\left.\mathrm{OH})_{12}\left(\mathrm{O}_{2} \mathrm{C}-\right)_{12}\right]$, and their subsequent copolymerization by the fully deprotonated octacarboxylate ligands (TBCPB) to yield a novel 3-periodic highly-connected Y-MOF. Each of the three yttrium ions is coordinated to four $\mu_{3}-\mathrm{OH}$, four oxygen from carboxylates, leaving the ninth coordination site occupied by a water molecule while each of the other six yttrium ions is surrounded by one $\mu_{3}-\mathrm{O}$, four $\mu_{3}-\mathrm{OH}$, two oxygen from carboxylates and one water molecule or $\mathrm{OH}$ in the apical position

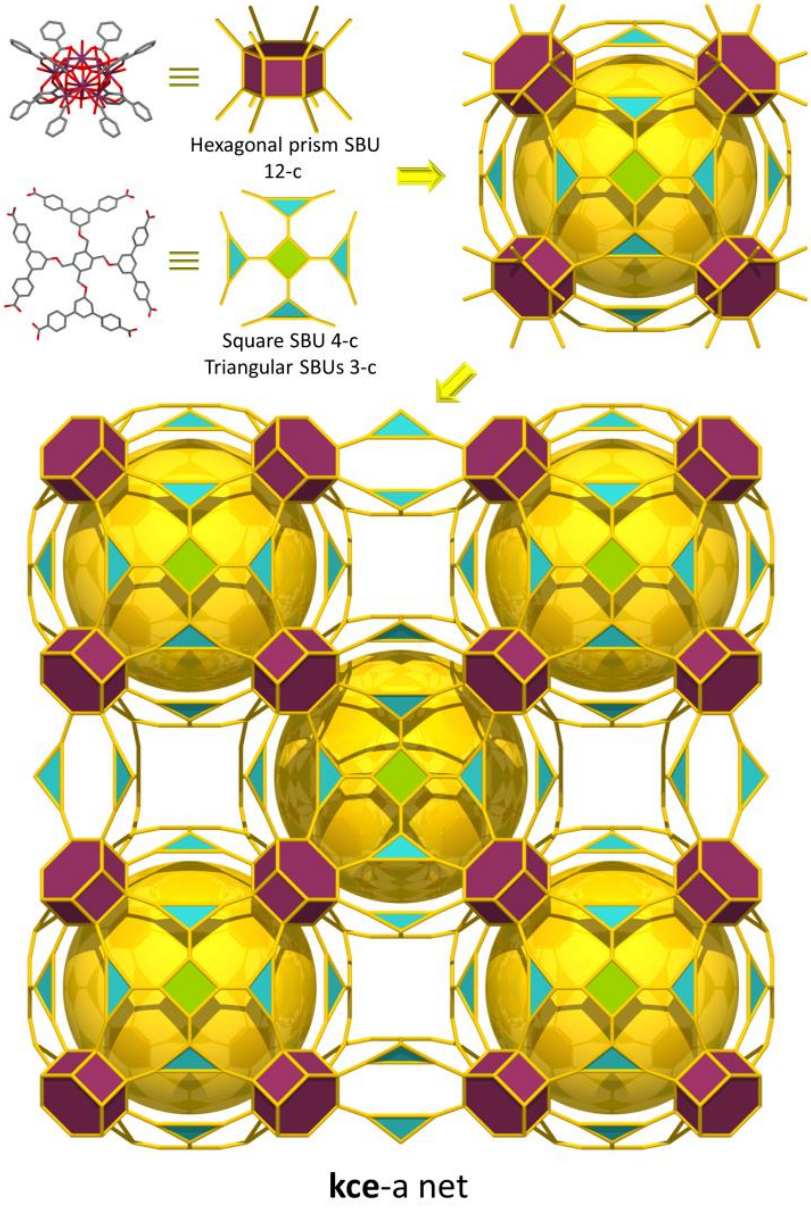

Figure 2. (top left) the nonanuclear RE cluster $\left[\mathrm{Y}_{9}\left(\mu_{3}-\mathrm{O}\right)_{2}\left(\mu_{3^{-}}\right.\right.$ $\left.\mathrm{OH})_{12}\left(\mathrm{O}_{2} \mathrm{C}-\right)_{12}\right]$ can be viewed as 12-connected hexagonal prism, and the octatopic ligand can be viewed as 3-connected triangles and 4-connected square, respectively; (top right) The cubic meso-cage is constructed by 8 hexagonal prisms, 24 triangles and 6 squares; (down) the assembly of meso-cages into infinite 3-periodic framework with underlying kce-a net. $\mathrm{RE}, \mathrm{C}$ and $\mathrm{O}$ are represented by purple, black and red, respectively, and $\mathrm{H}$ atoms and solvent molecules are omitted for clarity.

The resultant framework encloses one kind of cuboidal cages and two types of interconnected infinite channels (Figures S35). The cuboidal cage is constructed by six organic $\mathrm{TBCPB}^{8-}$ ligands located at the faces of the cube-shaped cage, and eight inorganic nonanuclear $\left[\mathrm{RE}_{9}\left(\mu_{3}-\mathrm{O}\right)_{2}\left(\mu_{3}-\mathrm{OH}\right)_{12}\left(\mathrm{O}_{2} \mathrm{C}-\right)_{12}\right]$ clusters, which occupy the vertices of the cubical cage. The corresponding calculated total accessible volume for Y-kce-MOF-1, upon removal of guest solvent molecules, was estimated to be $76.8 \%$, by summing voxels more than $1.2 \AA$ away from the framework using PLATON software. ${ }^{33}$

The phase purity of the bulk crystalline materials for compound 1 was confirmed by similarities between the calculated and as-synthesized powder X-ray diffraction (PXRD) patterns (Figure S15). The thermogravimetric analysis (TGA, Figure S16) shows that 1 decomposes at about $400{ }^{\circ} \mathrm{C}$ under $\mathrm{N}_{2}$ flow. As expected, substitution of the yttrium metal salt with $\mathrm{Tb}\left(\mathrm{NO}_{3}\right)_{3} \cdot 5 \mathrm{H}_{2} \mathrm{O}$ under similar reaction conditions resulted in the analogous Tb-kce-MOF-1, confirmed by PXRD and TGA data (Figures S17-18). 
Topological analysis of the resulting crystal structure revealed that the octatopic ligand which can be deconstructed into one 4-connected square node and four topologically same 3connected nodes, in combination with the aforesaid 12-c d6R $\mathrm{MBB}, \quad\left[\mathrm{Y}_{9}\left(\mu_{3}-\mathrm{O}\right)_{2}\left(\mu_{3}-\mathrm{OH}\right)_{12}\left(\mathrm{O}_{2} \mathrm{C}-\right)_{12}\right]$, resulted in the formation of an unprecedented highly-connected Y-MOF with a $(3,4,12)$-connected net and kce underlying topology, Y-kceMOF-1 (Figures 2 and S10). It is worth to note that the trinodal kce net has the transitivity [3232], a minimal edge transitive net with only two kind of edge. This $(3,4,12)$-c kce net is related to the $(4,6)-\mathrm{c}$ soc net.

\section{RE-kex-MOF-1 Platform.}

In order to further attest the principle that the highlycoordinated minimal edge-transitive nets with d6R MBBs are suitable targets for the rational construction of highlyconnected MOFs, a pre-programmed 12-carboxylate ligand enclosing both triangle and hexagon MBBs was also purposely deployed in combination with the RE polynuclear clusters to construct said the targeted minimal edge-transitive related net $(3,6,12)$-c kex net.

Indeed, reactions between $\mathrm{Y}\left(\mathrm{NO}_{3}\right)_{3} \cdot 6 \mathrm{H}_{2} \mathrm{O}$ and 1,2,3,4,5,6hexakis[3,5-bis(4-carboxyphenyl)phenoxymethyl]benzene $\mathrm{DMF} /$ chlorobenzene/water solution yielded colorless hexagonal crystals, formulated by SCXRD as $\left|(\mathrm{DMA})_{3}\right|\left[\mathrm{Y}_{9}\left(\mu_{3}-\mathrm{O}\right)_{2}\left(\mu_{3}-\right.\right.$ $\left.\mathrm{OH})_{12}(\mathrm{OH})_{2}\left(\mathrm{H}_{2} \mathrm{O}\right)_{7}(\mathrm{HBCPB})\right] \cdot(\text { solv })_{x}$ (kex-MOF-1) (2) (Table S2; Figures 3 and S6). The SCXRD study discloses that compound 2 crystallizes in the hexagonal space group $P 6_{3} / m$ with $a=23.951(1) \AA, c=32.354(2) \AA$ and $V=16073(2) \AA^{3}$. Analysis of the resultant crystal structure of 2 reveals the in situ formation of highly-connected yttrium polynuclear carboxylate-based clusters, namely a 12-c Y nonanuclear clusters $\left[\mathrm{RE}_{9}\left(\mu_{3}-\mathrm{O}\right)_{2}\left(\mu_{3}-\mathrm{OH}\right)_{12}\left(\mathrm{O}_{2} \mathrm{C}-\right)_{12}\right]$, and their subsequent copolymerization by the fully deprotonated dodecacarboxylate ligands (HBCPB) to yield a novel 3-periodic highly-connected Y-kex-MOF-1. The replacement of the yttrium metal salts with $\mathrm{Tb}\left(\mathrm{NO}_{3}\right)_{3} \cdot 5 \mathrm{H}_{2} \mathrm{O}$ under similar reaction conditions resulted in the analogous Tb-kex-MOF-1, |(DMA $)_{3} \mid\left[\mathrm{Tb}_{9}\left(\mu_{3}-\mathrm{O}\right)_{2}\left(\mu_{3}-\right.\right.$ $\left.\mathrm{OH})_{12}(\mathrm{OH})_{2}\left(\mathrm{H}_{2} \mathrm{O}\right)_{7}(\mathrm{HBCPB})\right] \cdot(\text { solv })_{x}($ 2-Tb) (Table S3).

The resultant framework encloses two kinds of cages, namely cage A constructed from five nonanuclear clusters and six organic ligands, and cage B formed by three inorganic clusters and two deprotonated dodecacarboxylate linkers (Figure S6). The close examination of the RE-kex-MOF-1 structure revealed the nonanuclear cluster MBBs arrange to form 2periodic hexagonal lattice (hxl) layers in the $a b$ plane, pillared by HBCPB ligands thus resulting in a 3-periodic MOF (Figures S7-8). Explicitly, the hxl layers are pillared in an ABA packing mode. The corresponding solvent accessible free volume for compound 2 was estimated to be $11069 \AA^{3}(70.0 \%$ of the unit cell volume of $15867 \AA^{3}$ ) by summing voxels more than $1.2 \AA$ away from the framework using PLATON software. ${ }^{33}$

The phase purity of the bulk crystalline materials for compound $\mathbf{2}$ and $\mathbf{2 - T b}$ were confirmed by similarities between the calculated PXRD patterns from the SCXRD data and assynthesized patterns (Figures S19 and S21). The TGA plots under $\mathrm{N}_{2}$ flow revealed these compounds decompose at $\sim 450{ }^{\circ} \mathrm{C}$ (Figures $\mathbf{S 2 0}$ and $\mathbf{S 2 2}$ ).

Topological analysis of the resulting crystal structure revealed that the dodecacarboxylate ligand which can be deconstructed $\left(\mathrm{H}_{12} \mathrm{HBCPB}\right)$, in the presence of 2 -FBA in an into one 6-connected hexagon node and six topologically same 3 -connected nodes, in combination with the aforementioned 12-c MBB, $\left[\mathrm{Y}_{9}\left(\mu_{3}-\mathrm{O}\right)_{2}\left(\mu_{3}-\mathrm{OH}\right)_{12}\left(\mathrm{O}_{2} \mathrm{C}-\right)_{12}\right]$, resulted in the formation of the unique highly-connected $\mathrm{Y}-\mathrm{MOF}$ with a $(3,6,12)$-connected net and kex underlying topology, Y-kexMOF-1 (Figures 3 and S11). It is to be noted that the $(3,6,12)-$ c kex net is related to the edge transitive $(6,6)$-c nia net, and that the trinodal kex net has the transitivity [3243], a minimal edge transitive net with only two kind of edges.
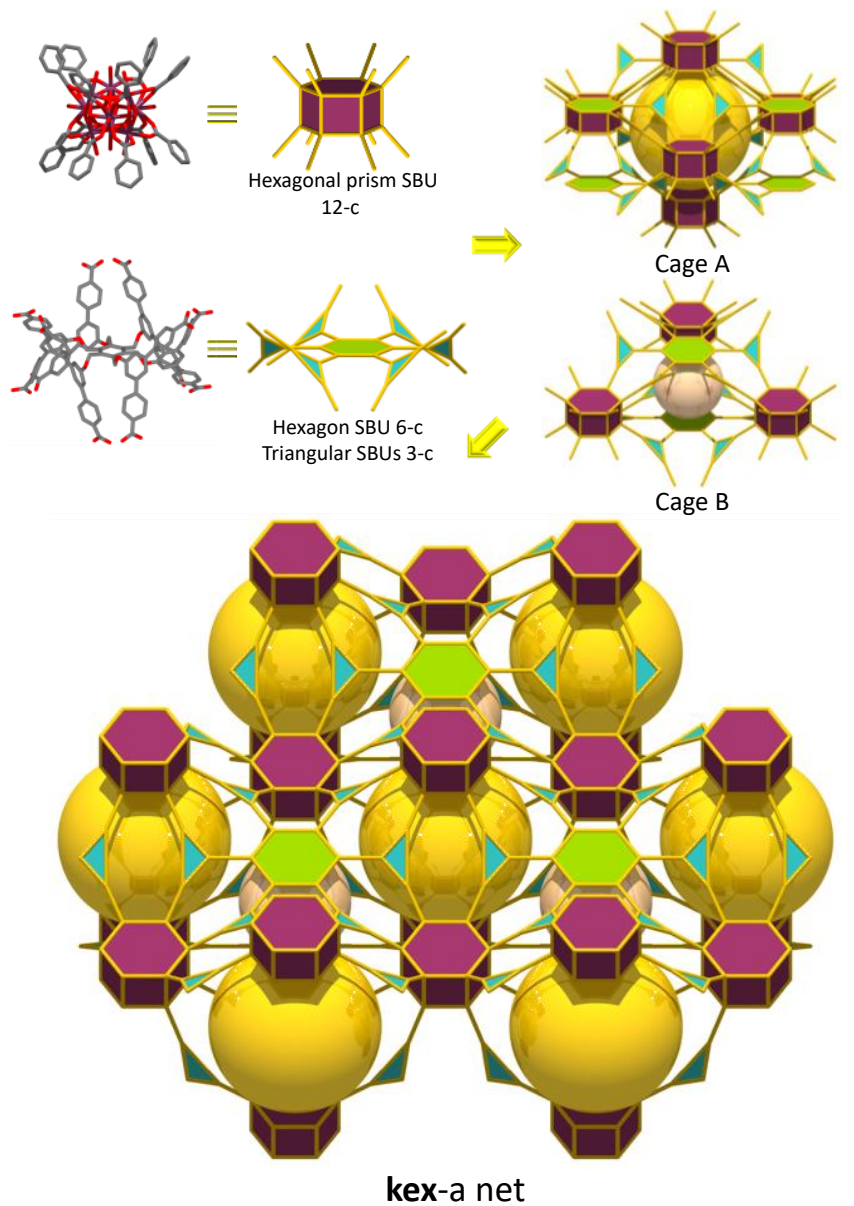

Figure 3. (top left) the nonanuclear RE cluster $\left[\mathrm{Y}_{9}\left(\mu_{3}-\mathrm{O}\right)_{2}\left(\mu_{3}-\right.\right.$ $\mathrm{OH})_{12}\left(\mathrm{O}_{2} \mathrm{C}-\right)_{12}$ ] can be viewed as 12 -connected hexagonal prism, and the dodecatopic ligand can be viewed as 3connected triangles and 6-connected hexagon, respectively; (top right) The trigonal bipyramidal cage $\mathrm{A}$ is constructed by 5 hexagonal prisms, 12 triangles and 6 hexagons, while the trigonal bipyramidal cage $\mathrm{B}$ is constructed by 3 hexagonal prisms, 12 triangles and 2 hexagons; (down) the assembly of cages into infinite 3-periodic framework with underlying kex-a net. $\mathrm{RE}, \mathrm{C}$ and $\mathrm{O}$ are represented by purple, black and red, respectively, and $\mathrm{H}$ atoms and solvent molecules are omitted for clarity.

ZMOFs area subclass of MOFs with topologies and, in some cases, with features similar to traditional inorganic zeolites, a benchmark in porous solid-state materials due to their notable commercial significance. ${ }^{26}$ ZMOFs attracted open scientific interest due to their tunable pore size/shape, unique cage-like cavities, as well as modular intra- and/or extra-framework components. To delineate pathways toward the rational design and construction of ZMOFs, several key design routes (i.e. 
"edge-expansion" of traditional zeolitic net, assembly from hierarchically superior building units, derivation from enlarged tetrahedral building units; construction via organic tetrahedral nodes) are accessible. ${ }^{26}$

Composite building units (CBUs) are the basic building blocks for zeolites, containing double four-membered ring (d4R), double six-membered ring (d6R), double eight-membered ring (d8R) etc. ${ }^{34}$ The $d 6 \mathrm{R}$ is a key composite building unit in zeolites such as Faujasite and SAPO-56; however, to the best of our knowledge, no example of ZMOFs based on the organic d6Rs has been reported so far due to the extreme difficulty pertaining to the formation of d6R MBBs inside MOFs. It should be noted that $\mathrm{d} 4 \mathrm{Rs}$ and $\mathrm{d} 8 \mathrm{Rs}$ have already been used to construct ZMOFs (i.e. rho-ZMOF ${ }^{35}$ and lta-ZMOF ${ }^{36}$ ) and zeolitic imidazolate frameworks (ZIFs) (i.e. ZIF-10 ${ }^{37-38}$ ) since a decade ago. Recently, the d6R building units have been used to construct ZIFs such as ZIF-386 with the afx net. ${ }^{27}$

Herein, by considering the ligands of the aforementioned kexMOF-1 as the 12-connected nodes, the kex-MOFs can alternatively be viewed as a MOF constructed from only d6Rs, namely the combination of the $d 6 R$ shaped ligands and the d6R inorganic polynuclear clusters. Topological analysis of the resulting net reveals that this MOF is the first example of afxZMOF with both organic and inorganic d6Rs, enclosing one kind of gme cage and one kind of aft cage (Figure 4 and S12). The comparison of cages in kex-a net (cage A and cage B), cages in zeolitic afx net (aft and gme cage), and natural tiling in afx-ZMOF (aft and gme tiling) revealed the intrinsic relationship between the newly generated kex net and known zeolitic afx net (Figure S9).

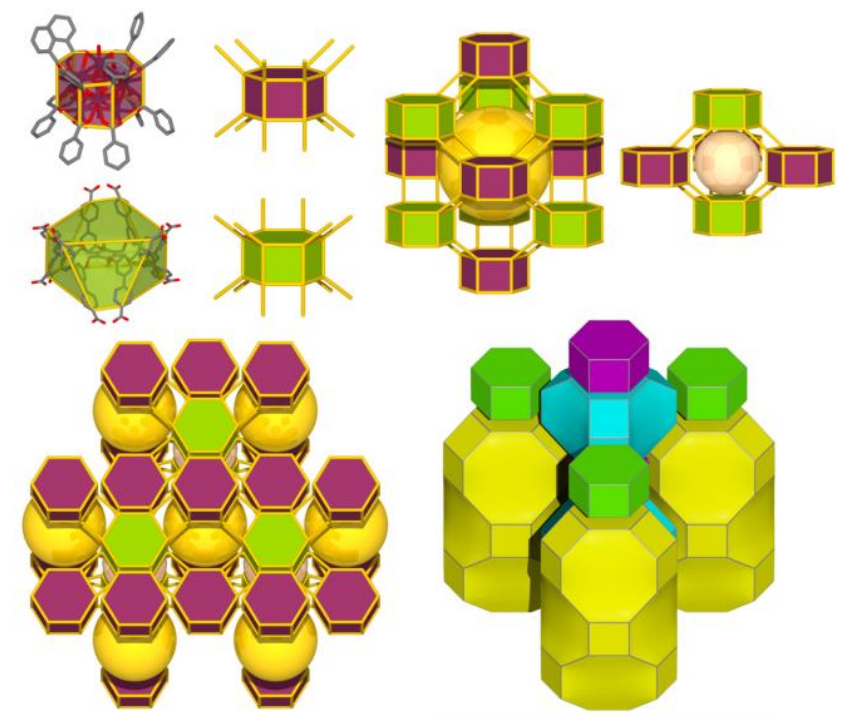

Figure 4. (top left) the nonanuclear RE cluster $\left[\mathrm{Y}_{9}\left(\mu_{3}-\mathrm{O}\right)_{2}\left(\mu_{3^{-}}\right.\right.$ $\left.\mathrm{OH})_{12}\left(\mathrm{O}_{2} \mathrm{C}-\right)_{12}\right]$ can be viewed as 12-connected hexagonal prism (d6R-1, purple), and the dodecatopic ligand can be viewed as 12-connected hexagonal prism (d6R-2, green), respectively; (top right) The trigonal bipyramidal cage $\mathrm{A}$ is constructed by 5 d6Rs- 1 and 6 d6Rs-2, while the trigonal bipyramidal cage $B$ is constructed by 3 d6Rs- 1 and 2 d6Rs-2; (down left) the assembly of cages into infinite 3-periodic framework with underlying afx net; (down right) natural tiling of afx-ZMOF (d6Rs-1 are shown in purple, d6Rs-2 in green, gme cages in light blue, aft cages in yellow). RE, $\mathrm{C}$ and $\mathrm{O}$ are represented by purple, black and red, respectively, and $\mathrm{H}$ atoms and solvent molecules are omitted for clarity.
RE-urx-MOF-1 Platform.

In order to further prove that minimal edge-transitive related nets (i.e. $(3,6,12)$-c urx net with triangle, trigonal antiprism and d6R building units) are special and suitable blueprint nets for the rational construction of highly-connected MOFs, a 3connected heterofunctional ligand was also purposely deployed in combination with the RE polynuclear clusters. It is to be noted that the combination of triangular ligands with lower symmetry and RE polynuclear clusters tend to form structures containing layers of 12-c nanonuclear clusters (d6R) and different polynuclear cluster based MBBs, namely pekMOFs (triangle, cube and d6R) and aea-MOFs (triangle, d6R1 and d6R-2).${ }^{19}$ Herein, the introduction of 3-c heterofunctional ligand with the tetrazolate moiety offers the potential to plausibly direct the formation of tetrazolate-based polynuclear $\mathrm{RE}$ cluster with a novel vertex figures, and plausibly lead to the construction of MOFs based on urx topology.

Indeed, reactions between $\mathrm{Tb}\left(\mathrm{NO}_{3}\right)_{3} \cdot 6 \mathrm{H}_{2} \mathrm{O}$ and the heterofunctional 5'-(1H-tetrazol-5-yl)-1,1': $3^{\prime}, 1^{\prime \prime}$-terphenyl-4,4" dicarboxylic acid ( $\mathrm{H}_{3}$ TTDA), in the presence of 2-FBA in an $\mathrm{DMF} /$ chlorobenzene/water solution yielded colorless hexagonal crystals, formulated by SCXRD as $\left|(\mathrm{DMA})_{5}\right|\left[\left(\mathrm{Tb}_{9}\left(\mu_{3}-\right.\right.\right.$ $\left.\mathrm{O})_{2}\left(\mu_{3}-\mathrm{OH}\right)_{12}(\mathrm{OH})_{2}\left(\mathrm{H}_{2} \mathrm{O}\right)_{7}\right) \quad\left(\mathrm{Tb}_{6}\left(\mu_{3}-\mathrm{OH}\right)_{8}\left(\mathrm{H}_{2} \mathrm{O}\right)_{6}(\mathrm{HCOO})_{6}\right)$ $\left.(\text { TTDA })_{6}\right] \cdot(\text { solv })_{x}$ (urx-MOF-1) (3) (Table S4; Figure 5). The SCXRD study discloses that compound $\mathbf{3}$ crystallizes in the hexagonal space group $P 6_{3} / m m c$ with $a=22.7138(9) \AA$, $c=$ 50.592(2) $\AA$ and $V=22604(2) \AA^{3}$. Analysis of the resultant crystal structure of 3 reveals the in situ formation of both highly-connected terbium ( $\mathrm{Tb})$ 12-c nonanuclear carboxylatebased cluster and terbium 6-c hexanuclear tetrazolate-based cluster, and their subsequent copolymerization by the fully deprotonated TTDA ligand to yield a novel 3-periodic highlyconnected Tb-MOF.

The replacement of the terbium metal salts with $\mathrm{Dy}\left(\mathrm{NO}_{3}\right)_{3} \cdot 5 \mathrm{H}_{2} \mathrm{O}$ under similar reaction conditions with $\mathrm{NaH}_{2}$ TTDA resulted in the analogous Dy-urx-MOF-1, $\left|(\mathrm{DMA})_{5}\right|\left[\left(\mathrm{Na}_{2} \mathrm{Dy}_{9}\left(\mu_{3}-\mathrm{O}\right)_{2}\left(\mu_{3}-\mathrm{OH}\right)_{12}(\mathrm{O})_{2}\left(\mathrm{H}_{2} \mathrm{O}\right)_{7}\right) \quad\left(\mathrm{Dy}_{6}\left(\mu_{3^{-}}\right.\right.\right.$ $\left.\left.\mathrm{OH})_{8}(\mathrm{HCOO})_{6}\left(\mathrm{H}_{2} \mathrm{O}\right)_{6}\right)(\text { TTDA })_{6}\right] \cdot(\text { solv })_{x}($ 3-Dy) (Table S5).

Analysis of the hexanuclear cluster revealed that all the $\mathrm{Tb}$ ions are nine coordinated, seven oxygens (namely four from the $\mu_{3}-\mathrm{OH}$, two from the formate generated from-the in situ degradation of DMF solvent molecules, and one apical water molecule) and two nitrogen from the tetrazolate moiety of the ligand. The resulting $\left[\mathrm{Tb}_{6}\left(\mu_{3}-\mathrm{OH}\right)_{8}\left(\mathrm{H}_{2} \mathrm{O}\right)_{6}\left(\mathrm{O}_{2} \mathrm{CH}\right)_{6}\left(\mathrm{~N}_{4} \mathrm{C}-\right)_{6}\right]^{2-}$ cluster is capped by six tetrazolate moieties from six different ligands and six carboxylate groups from six formates.

Similarly, six of the $\mathrm{Tb}$ ions of the nonanuclear cluster are coordinated to eight oxygens (one from the $\mu_{3}-\mathrm{O}$, four from the $\mu_{3}-\mathrm{OH}$, two from the carboxylate of the ligand and one water molecule or $\mathrm{OH}$ in the apical position) while the remaining three $\mathrm{Tb}$ ions are coordinated to nine oxygens (four from the $\mu_{3}-\mathrm{OH}$, four from the carboxylate of the ligand and one water molecule in the apical position). The resulting $\left[\mathrm{Tb}_{9}\left(\mu_{3^{-}}\right.\right.$ $\left.\mathrm{O})_{2}\left(\mu_{3}-\mathrm{OH}\right)_{12}\left(\mathrm{O}_{2} \mathrm{C}-\right)_{12}(\mathrm{OH})_{2}\left(\mathrm{H}_{2} \mathrm{O}\right)_{7}\right]^{3-}$ is capped by twelve carboxylates from twelve different ligands. The overall charge of the structure is balanced by five DMA cations from the thermal decomposition of DMF. 


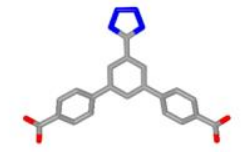

3-c ligand

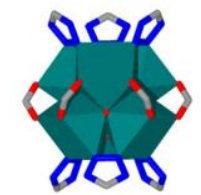

6-c hexanuclear cluster

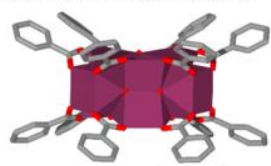

12-c nonanuclear cluster

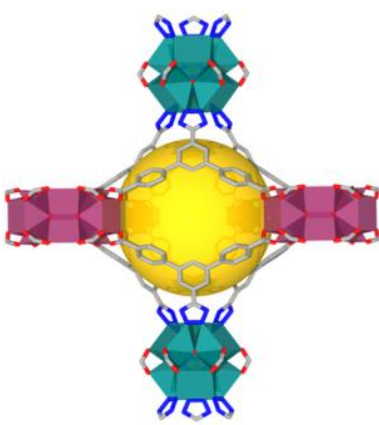

RE-urx-MOF-1
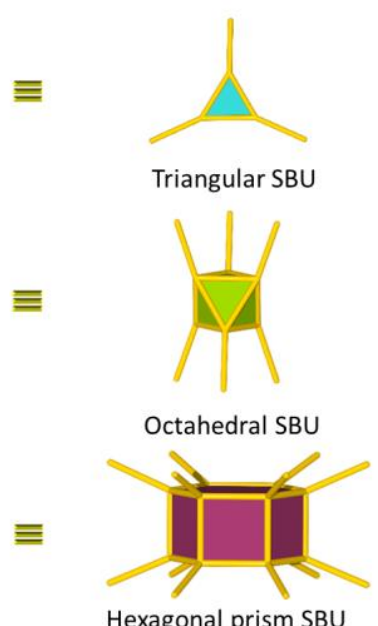

Hexagonal prism SBU

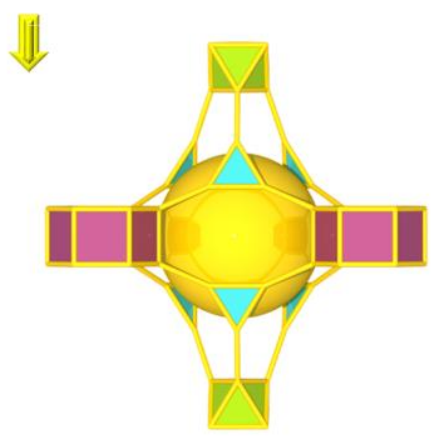

urx-a net
Figure 5. Use of a heterofunctional based 3-c ligand leading to the formation of a 6-connected hexanuclear cluster, $\left[\mathrm{Tb}_{6}\left(\mu_{3^{-}}\right.\right.$ $\left.\mathrm{OH})_{8}\left(\mathrm{H}_{2} \mathrm{O}\right)_{6}\left(\mathrm{O}_{2} \mathrm{CH}\right)_{6}\left(\mathrm{~N}_{4} \mathrm{C}-\right)_{6}\right]$, and a 12-connected nonanuclear cluster, $\left[\mathrm{Tb}_{9}\left(\mu_{3}-\mathrm{O}\right)_{2}\left(\mu_{3}-\mathrm{OH}\right)_{12}\left(\mathrm{O}_{2} \mathrm{C}-\right)_{12}\right]$ paving the way to the discovery of a $(3,6,12)$-c urx net.

The topological analysis of the crystal structure revealed that the 12-connected nonanuclear cluster can be described as a hexagonal prism (d6R) secondary building unit (SBU), while the point of extension of the 6-connected hexanuclear cluster match the vertex figures of an octahedral SBU. These two building units combined with the 3-connected triangular ligand gave the Tb-urx-MOF-1 with the targeted highlyconnected $(3,6,12)$-c urx net, topologically related to the edgetransitive $(6,6)-c$ nia net (Figure 5 and S13).

Tb-urx-MOF-1 exhibits two types of cages, I and II, cage I being seen as a channel. Cage I has diameters of $17.2 \AA$ (height) and $14 \AA$ (width), and is accessible via two different apertures, 4.3 and $6.3 \mathrm{~A}$, respectively. Moreover, cage I is derived from the triangular arrangement, in the equatorial plan, of three nonanuclear clusters and the capping by two hexanuclear clusters, in the two axial positions (triangular based bipyramidal geometry), while cage II has diameters of $17.8 \AA$ (height) and $13.0 \AA$ (width)

The phase purity of Tb-urx-MOF-1 was confirmed by similarities between the calculated PXRD patterns from the SCXRD data and the patterns of the as-synthesized materials (Figure S23). The compound is insoluble in common organic solvents. The TGA analysis carried out under nitrogen flow revealed the compound $\mathbf{3}$ decomposes at about $400{ }^{\circ} \mathrm{C}$ (Figure S24).

Gas sorption studies.
The porosity of the material Tb-urx-MOF-1 was confirmed by Ar adsorption at $87 \mathrm{~K}$. In fact, Tb-urx-MOF-1 showed a fully reversible type I isotherm. Tb-urx-MOF-1 has an apparent Brunauer-Emmett-Teller (BET) surface area, a Langmuir surface area and a total pore volume of $1590 \mathrm{~m}^{2} \cdot \mathrm{g}^{-1}, 1830$ $\mathrm{m}^{2} \cdot \mathrm{g}^{-1}$ and $0.66 \mathrm{~cm}^{-3} \cdot \mathrm{g}^{-1}$ respectively. The experimentally obtained total pore volumes are in good agreement with the associated theoretical values derived from SCXRD data, i.e., $0.82 \mathrm{~cm}^{3} \cdot \mathrm{g}^{-1}$ for Tb-urx-MOF-1. The pore size distribution (PSD) for RE-urx-MOF-1 was assessed using the Ar adsorption data (Figure S25) and revealed two type of pores, which are in good qualitative agreement with the above derived values from the corresponding crystal data. The apparent BET surface areas and pore volumes for Y-kce-MOF-1 and Y-kexMOF-1 were provided in the Table S6. The lower experimental values of porosity compared to the simulated values might be due to partial activation or the inherent flexibility of these MOFs (Figures S26-27).

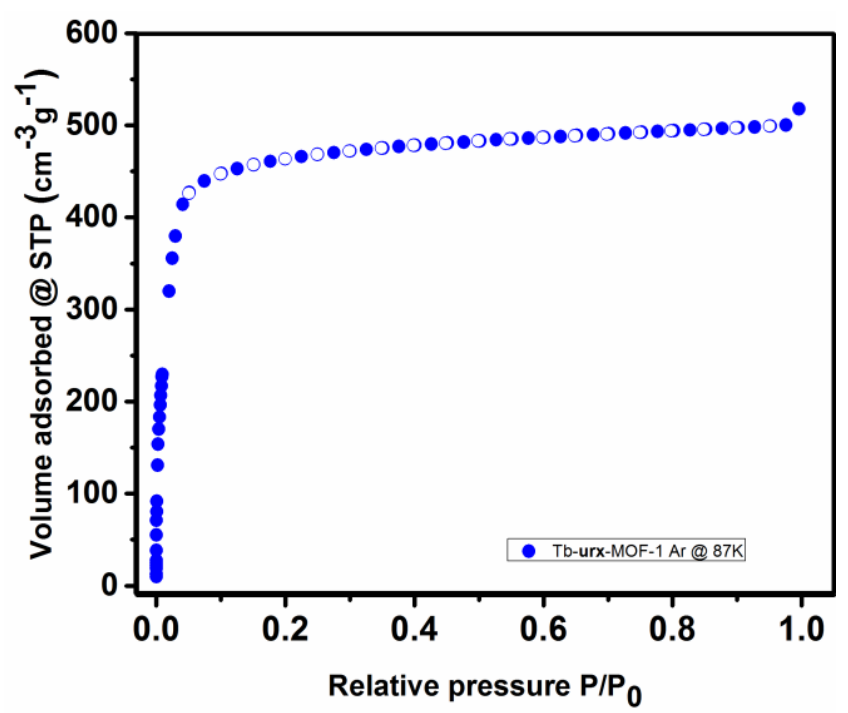

Figure 6. Type I isotherm for Argon sorption of Tb-urxMOF-1.

\section{CONCLUSIONS}

We reported here the employment of the minimal edgetransitive related trinodal nets for the rational design and synthesis of three types of highly-connected MOFs, namely $(3,4,12)$-c kce-, $(3,6,12)$-c kex-, and $(3,6,12)$-c urx-MOFs, containing d6Rs as net-cBUs. The kce-MOF-1 was synthesized by the use custom-designed octatopic ligands enclosing triangular and square building units, in combination with d6Rshaped RE polynuclear clusters in the presence of 2-FBA. The kex-MOF-1 was constructed using purposely-made dodecacarboxylate organic linkers as net-cBUs embedded with triangular and hexagonal building units, and the RE nanonuclear inorganic clusters. Notably, the ligands encompassed in kexMOF-1 can also be viewed as d6Rs, thus making it so far the first example of ZMOFs constructed from d6R organic MBBs with afx topology. The heterobifunctional triangular tetrazolebased ligand guided the in-situ formation of two kinds of polynuclear clusters, i.e. trigonal anti prismatic tetrazolate-based hexanuclear clusters and hexagonal prismatic carboxylatebased nanonuclear clusters, with the help of 2-FBA. Thus, it promoted to the construction of a 3 -periodic $(3,6,12)$-c urxMOF. 
The present work establishes a superior control in the rational design and assembly of novel MOF platforms by reticular chemistry. The newly generated minimal edge-transitive trinodal related nets, which have been included in searchable RCSR database, offer a commanding route for the design and construction of highly-coordinated crystalline extended framework materials using highly-connected building blocks. We also unveiled the importance of minimal edge-transitive related nets as appropriate blueprints for the design and directed assembly of MOFs with net-cBUs. The requisite netcBUs can attained as highly-connected inorganic MBBs, which are in-situ generated under the right reaction conditions, and/or from a polytopic organic ligand encompassing the precise connectivity that affords the positioning of coordinating moieties in the intricate and desired highly-connected geometry. Most importantly, we revealed that the systematic generation of minimal edge-transitive related net from the parent edge-transitive net is a reliable process paving the way for the deliberate construction of highly-connected nets.

Noticeably, unprecedented control in the MOF design using minimal edge-transitive trinodal related nets offers great potential for the development of made-to-order MOFs with programmed functionalities to address the persisting needs in various on-demand applications such as gas storage, and gas/vapor separations.

\section{EXPERIMENTAL SECTION}

Synthesis of compounds.

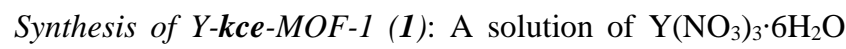
( $21.9 \mathrm{mg}, 0.06 \mathrm{mmol}$ ) and $\mathrm{H}_{8}$ TBCPB $(7.3 \mathrm{mg}, 0.005 \mathrm{mmol}$ ) in $1.25 \mathrm{~mL}$ of DMF, $0.75 \mathrm{~mL}$ chlorobenzene and $0.75 \mathrm{~mL}$ of $\mathrm{H}_{2} \mathrm{O}$ were mixed in a $20 \mathrm{~mL}$ scintillation vial. A $2 \mathrm{~mL}$ of $4 \mathrm{M}$ 2-FBA in DMF was added to the mixture, and then sonicated for $30 \mathrm{~min}$. The vial was sealed and heated to $105^{\circ} \mathrm{C}$ for $72 \mathrm{~h}$. The pure colorless polyhedron crystals were filtered and washed with DMF. The as-synthesized material was found to be insoluble in $\mathrm{H}_{2} \mathrm{O}$ and common organic solvents. Crystals were harvested, soaked in DMF overnight, and then exchanged in $\mathrm{CH}_{2} \mathrm{Cl}_{2}$ (DCM) for three days. Note that the DCM solution was refreshed at least every $12 \mathrm{~h}$. Tb-kce-MOF-1 was synthesized in the similar way as Y-kce-MOF-1 but by using $\mathrm{Tb}\left(\mathrm{NO}_{3}\right)_{3} \cdot 5 \mathrm{H}_{2} \mathrm{O}$ instead of $\mathrm{Y}\left(\mathrm{NO}_{3}\right)_{3} \cdot 6 \mathrm{H}_{2} \mathrm{O}$.

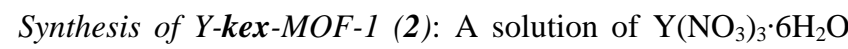
( $21.9 \mathrm{mg}, 0.06 \mathrm{mmol})$ and $\mathrm{H}_{12} \mathrm{HBCPB}(10.78 \mathrm{mg}, 0.005 \mathrm{mmol})$ in $1.25 \mathrm{~mL}$ of DMF, $0.75 \mathrm{~mL}$ chlorobenzene and $0.75 \mathrm{~mL}$ of $\mathrm{H}_{2} \mathrm{O}$ were mixed in a $20 \mathrm{~mL}$ scintillation vial. A $2 \mathrm{~mL}$ of $4 \mathrm{M}$ 2-FBA in DMF was added to the mixture, and then sonicated for $30 \mathrm{~min}$. The vial was sealed and heated to $105^{\circ} \mathrm{C}$ for $24 \mathrm{~h}$. The pure colorless hexagonal prism shape crystals were filtered and washed with DMF. The as-synthesized material was found to be insoluble in $\mathrm{H}_{2} \mathrm{O}$ and common organic solvents. Crystals were harvested, soaked in DMF overnight, and then exchanged in DCM for three days. Note that the DCM solution was refreshed at least every $12 \mathrm{~h}$. Tb-kex-MOF-1 (2-Tb) was synthesized in the similar way as Y-kex-MOF-1 but by using $\mathrm{Tb}\left(\mathrm{NO}_{3}\right)_{3} \cdot 5 \mathrm{H}_{2} \mathrm{O}$ instead of $\mathrm{Y}\left(\mathrm{NO}_{3}\right)_{3} \cdot 6 \mathrm{H}_{2} \mathrm{O}$.

Synthesis of Tb-urx-MOF-1 (3): A solution of $\mathrm{Tb}\left(\mathrm{NO}_{3}\right)_{3} \cdot 5 \mathrm{H}_{2} \mathrm{O}$ $(15 \mathrm{mg}, 0.04 \mathrm{mmol})$ and $\mathrm{H}_{3}$ TTDA $(8 \mathrm{mg}, 0.02 \mathrm{mmol})$ in $3 \mathrm{~mL}$ of DMF, $0.2 \mathrm{~mL}$ chlorobenzene and $0.5 \mathrm{~mL}$ of $\mathrm{H}_{2} \mathrm{O}$ were mixed in a $20 \mathrm{~mL}$ scintillation vial. A $0.155 \mathrm{~mL}$ of $4 \mathrm{M} 2$-FBA in DMF was added to the mixture, and then sonicated for 30 min. The vial was sealed and heated to $115^{\circ} \mathrm{C}$ for $72 \mathrm{~h}$. The pure colorless hexagonal prism shape crystals were filtered and washed with DMF. The as-synthesized material was found to be insoluble in common organic solvents. Crystals were harvested, soaked in DMF overnight, and then exchanged in $\mathrm{CH}_{3} \mathrm{CN}$ for three days. Note that the solution was refreshed at least every 12h. Dy-urx-MOF-1 (3-Dy) was synthesized in the similar way as Tb-urx-MOF-1 but by using Dy $\left(\mathrm{NO}_{3}\right)_{3} \cdot 5 \mathrm{H}_{2} \mathrm{O}$ and $\mathrm{NaH}_{2}$ TTDA instead of $\mathrm{Tb}\left(\mathrm{NO}_{3}\right)_{3} \cdot 5 \mathrm{H}_{2} \mathrm{O}$ and $\mathrm{H}_{3}$ TTDA.

\section{ASSOCIATED CONTENT}

\section{Supporting Information}

Detailed procedures for the synthesis of the organic ligands, PXRD, TGA, additional structural figures, adsorption isotherms, and single-crystal X-ray diffraction data (CIF). This material is available free of charge via the Internet at http://pubs.acs.org

\section{AUTHOR INFORMATION}

\section{Corresponding Author \\ mohamed.eddaoudi@kaust.edu.sa \\ Author Contributions \\ $\S$ Z.C. and Z.T. contributed equally. \\ Notes}

The authors declare no competing financial interests.

\section{ACKNOWLEDGMENT}

Research reported in this publication was supported by King $\mathrm{Ab}$ dullah University of Science and Technology (KAUST).

\section{REFERENCES}

(1) Furukawa, H.; Cordova, K. E.; O’Keeffe, M.; Yaghi, O. M. The chemistry and applications of metal-organic frameworks. Science 2013, 341, 1230444.

(2) Foo, M. L.; Matsuda, R.; Kitagawa, S. Functional hybrid porous coordination polymers. Chem. Mater. 2014, 26, 310-322.

(3) Mondloch, J. E.; Katz, M. J.; Isley Iii, W. C.; Ghosh, P.; Liao, P.; Bury, W.; Wagner, G. W.; Hall, M. G.; DeCoste, J. B.; Peterson, G. W.; Snurr, R. Q.; Cramer, C. J.; Hupp, J. T.; Farha, O. K. Destruction of chemical warfare agents using metal-organic frameworks. Nat. Mater. 2015, 14, 512-516.

(4) Zhang, T.; Lin, W. Metal-organic frameworks for artificial photosynthesis and photocatalysis. Chem. Soc. Rev. 2014, 43, 5982-5993.

(5) Campbell, M. G.; Liu, S. F.; Swager, T. M.; Dincă, M. Chemiresistive sensor arrays from conductive $2 \mathrm{~d}$ metal-organic frameworks. J. Am. Chem. Soc. 2015, 137, 13780-13783.

(6) Hu, Z.; Deibert, B. J.; Li, J. Luminescent metal-organic frameworks for chemical sensing and explosive detection. Chem. Soc. Rev. 2014, 43, 5815-5840.

(7) Jiang, J.; Furukawa, H.; Zhang, Y.-B.; Yaghi, O. M. High methane storage working capacity in metal-organic frameworks with acrylate links. J. Am. Chem. Soc. 2016, 138, 10244-10251.

(8) Li, B.; Wen, H.-M.; Zhou, W.; Xu, Jeff Q.; Chen, B. Porous metal-organic frameworks: Promising materials for methane storage. Chem 2016, 1, 557-580.

(9) Alezi, D.; Belmabkhout, Y.; Suyetin, M.; Bhatt, P. M.; Weseliński, Ł. J.; Solovyeva, V.; Adil, K.; Spanopoulos, I.; Trikalitis, P. N.; Emwas, A.-H.; Eddaoudi, M. MOF crystal chemistry paving the way to gas storage needs: Aluminum-based soc-MOF for $\mathrm{CH}_{4}, \mathrm{O}_{2}$, and $\mathrm{CO}_{2}$ storage. J. Am. Chem. Soc. 2015 , 137, 13308-13318. 
(10) Cadiau, A.; Adil, K.; Bhatt, P. M.; Belmabkhout, Y.; Eddaoudi, M. A metal-organic framework-based splitter for separating propylene from propane. Science 2016, 353, 137-140.

(11) Adil, K.; Belmabkhout, Y.; Pillai, R. S.; Cadiau, A.; Bhatt, P. M.; Assen, A. H.; Maurin, G.; Eddaoudi, M. Gas/vapour separation using ultra-microporous metal-organic frameworks: Insights into the structure/separation relationship. Chem. Soc. Rev. 2017, 46, 3402-3430.

(12) Cui, X.; Chen, K.; Xing, H.; Yang, Q.; Krishna, R.; Bao, Z.; Wu, H.; Zhou, W.; Dong, X.; Han, Y.; Li, B.; Ren, Q.; Zaworotko, M. J.; Chen, B. Pore chemistry and size control in hybrid porous materials for acetylene capture from ethylene. Science 2016, 353, 141-144.

(13) Yaghi, O. M.; O'Keeffe, M.; Ockwig, N. W.; Chae, H. K.; Eddaoudi, M.; Kim, J. Reticular synthesis and the design of new materials. Nature 2003, 423, 705-714.

(14) Eddaoudi, M.; Kim, J.; Rosi, N.; Vodak, D.; Wachter, J.; O'Keeffe, M.; Yaghi, O. M. Systematic design of pore size and functionality in isoreticular MOFs and their application in methane storage. Science 2002, 295, 469-472.

(15) Yaghi, O. M.; Kalmutzki, M. J.; Diercks, C. S., Introduction to reticular chemistry: Metal-organic frameworks and covalent organic frameworks. John Wiley \& Sons: 2019.

(16) Li, M.; Li, D.; O’Keeffe, M.; Yaghi, O. M. Topological analysis of metal-organic frameworks with polytopic linkers and/or multiple building units and the minimal transitivity principle. Chem. Rev. 2014, 114, 1343-1370.

(17) Xue, D.-X.; Cairns, A. J.; Belmabkhout, Y.; Wojtas, L.; Liu, Y.; Alkordi, M. H.; Eddaoudi, M. Tunable rare-earth fcu-MOFs: A platform for systematic enhancement of $\mathrm{CO} 2$ adsorption energetics and uptake. J. Am. Chem. Soc. 2013, 135, 7660-7667.

(18) Liu, T. F.; Feng, D.; Chen, Y. P.; Zou, L.; Bosch, M.; Yuan, S.; Wei, Z.; Fordham, S.; Wang, K.; Zhou, H. C. Topologyguided design and syntheses of highly stable mesoporous porphyrinic zirconium metal-organic frameworks with high surface area. J. Am. Chem. Soc. 2015, 137, 413-9.

(19) Alezi, D.; Peedikakkal, A. M. P.; Weseliński, Ł. J.; Guillerm, V.; Belmabkhout, Y.; Cairns, A. J.; Chen, Z.; Wojtas, Ł.; Eddaoudi, M. Quest for highly connected metal-organic framework platforms: Rare-earth polynuclear clusters versatility meets net topology needs. J. Am. Chem. Soc. 2015, 137, 54215430.

(20) Chen, Z.; Weseliński, Ł. J.; Adil, K.; Belmabkhout, Y.; Shkurenko, A.; Jiang, H.; Bhatt, P. M.; Guillerm, V.; Dauzon, E.; Xue, D.-X.; O'Keeffe, M.; Eddaoudi, M. Applying the power of reticular chemistry to finding the missing alb-MOF platform based on the $(6,12)$-coordinated edge-transitive net. J. Am. Chem. Soc. 2017, 139, 3265-3274.

(21) Chen, Z.; Hanna, S. L.; Redfern, L. R.; Alezi, D.; Islamoglu, T.; Farha, O. K. Reticular chemistry in the rational synthesis of functional zirconium cluster-based MOFs. Coord. Chem. Rev. 2019, 386, 32-49.

(22) Muldoon, P. F.; Liu, C.; Miller, C. C.; Koby, S. B.; Gamble Jarvi, A.; Luo, T.-Y.; Saxena, S.; O’Keeffe, M.; Rosi, N. L. Programmable topology in new families of heterobimetallic metal-organic frameworks. J. Am. Chem. Soc. 2018, 140, 61946198.

(23) Liu, Q.; Song, Y.; Ma, Y.; Zhou, Y.; Cong, H.; Wang, C.; $\mathrm{Wu}$, J.; Hu, G.; O'Keeffe, M.; Deng, H. Mesoporous cages in chemically robust MOFs created by a large number of vertices with reduced connectivity. J. Am. Chem. Soc. 2019, 141, 488-496.
(24) Chen, Z.; Jiang, H.; O'Keeffe, M.; Eddaoudi, M. Minimal edge-transitive nets for the design and construction of metalorganic frameworks. Faraday Discuss. 2017, 201, 127-143.

(25) O'Keeffe, M.; Peskov, M. A.; Ramsden, S. J.; Yaghi, O. M. The reticular chemistry structure resource (RCSR) database of, and symbols for, crystal nets. Acc. Chem. Res. 2008, 41, 17821789.

(26) Eddaoudi, M.; Sava, D. F.; Eubank, J. F.; Adil, K.; Guillerm, V. Zeolite-like metal-organic frameworks (ZMOFs): Design, synthesis, and properties. Chem. Soc. Rev. 2015, 44, 228-249.

(27) Yang, J.; Zhang, Y.-B.; Liu, Q.; Trickett, C. A.; GutiérrezPuebla, E.; Monge, M. Á.; Cong, H.; Aldossary, A.; Deng, H.; Yaghi, O. M. Principles of designing extra-large pore openings and cages in zeolitic imidazolate frameworks. J. Am. Chem. Soc. 2017, 139, 6448-6455.

(28) Eubank, J. F.; Nouar, F.; Luebke, R.; Cairns, A. J.; Wojtas, Ł.; Alkordi, M.; Bousquet, T.; Hight, M. R.; Eckert, J.; Embs, J. P.; Georgiev, P. A.; Eddaoudi, M. On demand: The singular rht net, an ideal blueprint for the construction of a metal-organic framework (MOF) platform. Angew. Chem. Int. Ed. 2012, 51, 10099-10103.

(29) Delgado-Friedrichs, O.; O'Keeffe, M.; Yaghi, O. M. Threeperiodic nets and tilings: Edge-transitive binodal structures. Acta Cryst. A 2006, 62, 350-355.

(30) Gilson, S. E.; Li, P.; Szymanowski, J. E. S.; White, J.; Ray, D.; Gagliardi, L.; Farha, O. K.; Burns, P. C. In situ formation of unprecedented neptunium-oxide wheel clusters stabilized in a metal-organic framework. J. Am. Chem. Soc. 2019, 141, 1184211846.

(31) Feng, D.; Gu, Z.-Y.; Chen, Y.-P.; Park, J.; Wei, Z.; Sun, Y.; Bosch, M.; Yuan, S.; Zhou, H.-C. A highly stable porphyrinic zirconium metal-organic framework with shp-a topology. J. Am. Chem. Soc. 2014, 136, 17714-17717.

(32) Chen, Z.; Li, P.; Wang, X.; Otake, K.-i.; Zhang, X.; Robison, L.; Atilgan, A.; Islamoglu, T.; Hall, M. G.; Peterson, G. W.; Stoddart, J. F.; Farha, O. K. Ligand-directed reticular synthesis of catalytically active missing zirconium-based metal-organic frameworks. J. Am. Chem. Soc. 2019, 141, 12229-12235.

(33) Spek, A. Structure validation in chemical crystallography. Acta Cryst. D 2009, 65, 148-155.

(34) Baerlocher, C.; McCusker, L. B. Database of Zeolite Structures 2008, http://www.iza-structure.org/databases/.

(35) Liu, Y.; Kravtsov, V. C.; Larsen, R.; Eddaoudi, M. Molecular building blocks approach to the assembly of zeolitelike metal-organic frameworks (ZMOFs) with extra-large cavities. Chem. Commun. 2006, 1488-1490.

(36) Alkordi, M. H.; Brant, J. A.; Wojtas, L.; Kravtsov, V. C.; Cairns, A. J.; Eddaoudi, M. Zeolite-like metal-organic frameworks (ZMOFs) based on the directed assembly of finite metal-organic cubes (mocs). J. Am. Chem. Soc. 2009, 131, 17753-17755.

(37) Park, K. S.; Ni, Z.; Côté, A. P.; Choi, J. Y.; Huang, R.; Uribe-Romo, F. J.; Chae, H. K.; O'Keeffe, M.; Yaghi, O. M. Exceptional chemical and thermal stability of zeolitic imidazolate frameworks. Proc. Natl. Acad. Sci. U.S.A. 2006, 103, 1018610191.

(38) Ramirez, J. R.; Yang, H.; Kane, C. M.; Ley, A. N.; Holman, K. T. Reproducible synthesis and high porosity of mer-zn(im)2 (ZIF-10): Exploitation of an apparent double-eight ring template. J. Am. Chem. Soc. 2016, 138, 12017-12020. 


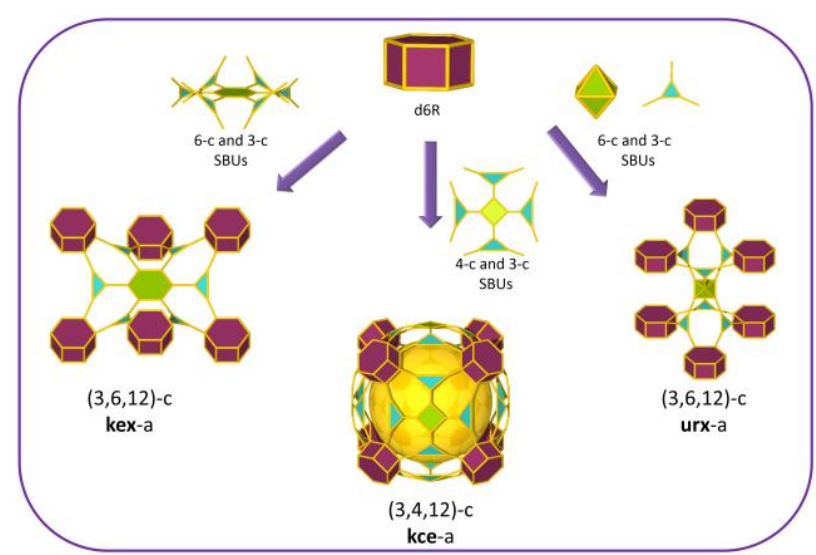

